\title{
Jogo computacional 3D em primeira pessoa: uma possibilidade para o ensino de química
}

\section{RESUMO}

Haroldo Luis Ribas Luis Ribas haroldordr@yahoo.com.br 0000-0003-1131-8295 Universidade Tecnológica Federal do Paraná, Curitiba, Paraná, Brasil.

Fabiana Roberta Gonçalves e Silva Hussein

fabianah@utfpr.edu.br

0000-0001-9961-7083

Universidade Tecnológica Federal

do Paraná, Curitiba, Paraná, Brasil.

Carlos Alberto Marques

bebetomarques07@gmail.com

0000-0002-4024-7695

Universidade Federal de Santa

Catarina, Florianópolis, Santa

Catarina, Brasil.
Nas últimas duas décadas, a utilização dos computadores tem se intensificado no ambiente escolar. A tecnologia envolvida no ambiente computacional tornou-se indissociável do cotidiano dos estudantes, de forma que o lúdico ganhou importância e os jogos computacionais tornaram-se rotina. Esse artigo analisa um jogo computacional 3D em primeira pessoa que aborda conteúdos de Físico-Química no contexto da abordagem de Ciência, Tecnologia e Sociedade - CTS. As questões propostas no jogo são analisadas como objetivo de identificar a presença de aspectos CTS, conteúdos de Química e situações que caracterizem o estímulo ao aprendizado. O caráter lúdico é analisado no jogo como um todo. As análises baseiam-se na metodologia da análise de conteúdo de Laurence Bardin. Os resultados obtidos nas análises indicam que ele contempla de forma adequada os conteúdos de química propostos, dentro do contexto da abordagem CTS e possui as características que o tornam uma atividade lúdica, apropriada para o ensino.

PALAVRAS-CHAVE: Jogos computacionais. Ensino de química. CTS. Ludicidade. 


\section{INTRODUÇÃO}

O jogo 3D em primeira pessoa, objeto dessa análise, foi desenvolvido a partir de uma demanda identificada quando tivemos contato com jogos computacionais para o ensino de química. A partir de pesquisas realizadas em anais de eventos, como ENEQ, ENPEQ, SBQ, e em sites de universidades brasileiras, verificou-se que a quase totalidade dos jogos computacionais utilizados no ensino são realizados em duas dimensões.

Da mesma forma foram realizadas pesquisas em revistas internacionais como o Journal of Chemical Education, revista Futurelab do National Foundation for Educational Research in England and Wales e no Scientific Bulletin da universidade politécnica de Bucareste onde os estudos sobre realidade virtual e jogos 3D aplicados à educação são mais desenvolvidos. Nesses veículos de publicação científica, foi constatada a presença de pesquisas específicas sobre jogos computacionais $3 \mathrm{D}$ em primeira pessoa, constituindo-se assim na principal referência para o desenvolvimento desse trabalho.

Cabe aqui distinguir o tipo de jogo tratado nesse artigo. Existem basicamente dois (2) tipos de jogos computacionais: os jogos em duas dimensões são aqueles em que os gráficos são apresentados apenas nos eixos $x$ e y do plano cartesiano. Um jogo que representa essa categoria é o Jogo Super Mário ${ }^{1}$.

Já os jogos 3D incorporam, além dos eixos $x$ e y, o eixo $z$, que confere a sensação de profundidade ao jogo. Nesse contexto, surgiu a ideia de se ter, na área de ensino de química, uma ferramenta computacional que estivesse em consonância com os avanços tecnológicos e computacionais vivenciados pelos alunos.

Desenvolveu-se então um jogo 3D em primeira pessoa do tipo Open world ${ }^{2}$, chamado Chemistry Raiders. Esse jogo aborda conteúdos de físico-química, com enfoque de Ciência, Tecnologia e Sociedade - CTS. Esses conteúdos foram inspirados no livro Química Cidadã, volume 2 (Santos et al., 2013). O jogo foi desenvolvido com o auxílio da Game Engine ${ }^{3}$ Unity3D e está licenciado sob uma Licença Creative Commons com atribuição de uso livre não comercial/compartilhamento sob a mesma licença 4.0 Brasil.

A tela inicial do jogo, que será analisado neste trabalho, mostra uma cena em que o jogador entra na ilha, na Figura 1.

\footnotetext{
${ }^{1}$ Super Mario: jogo 3D que foi muito popular na década de 1990.

2 Open world: Jogo que não tem sequência definida de fases, o jogador pode percorrer qualquer fase a qualquer momento.

${ }^{3}$ Game Engine: em português, (motor de jogo) consiste em um programa para computador ou um conjunto de bibliotecas capazes de juntar e construir todos os elementos de um jogo em tempo real. Ela inclui motor gráfico para renderizar gráficos em 2D ou 3D, motor de física para detectar colisões e fazer animações, além de suporte para sons, inteligência artificial, gerenciamento de arquivos, programação, entre outros. Fonte: https://producaodejogos.com/game-engine/
} 
Figura 1: Visão da tela de início do Jogo Chemistry Raiders.

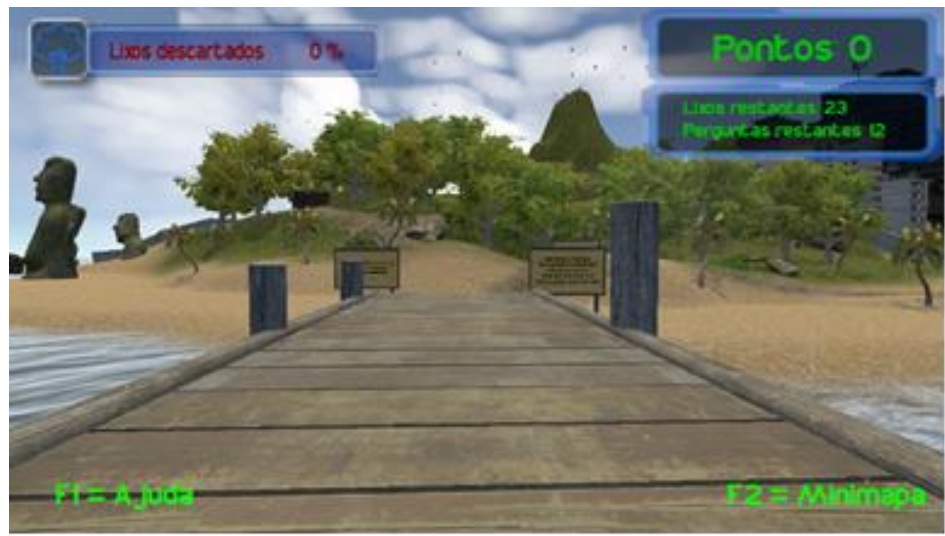

(Fonte: Jogo Chemistry Raiders.)

\section{REFERENCIAL TEÓRICO}

Atualmente, os recursos computacionais estão presentes em diversas áreas e atividades humanas tais como: Negócios, saúde, vida pessoal e lazer; caminhando a passos largos, inclusive, na educação.

Entre as inúmeras possibilidades e aplicações computacionais no ensino estão os jogos, que fascinam adolescentes, jovens e adultos.

Com o rápido desenvolvimento dos computadores pessoais, nas últimas duas décadas, os jogos computacionais se constituíram em uma poderosa ferramenta para o ensino.

Este artigo fundamenta-se na perspectiva de que as interações entre a Ciência, Tecnologia e Sociedade podem contribuir para uma reflexão crítica e tomada de decisão do estudante. Considera-se, portanto, o movimento CTS como ponto de partida para o desenvolvimento deste processo educativo que privilegia a reflexão e a responsabilidade social em assuntos que envolvem conteúdos científicos.

Segundo Santos e Schnetzler (apud TEIXEIRA, 2003), o movimento CTS teve origem em meados da década de 1970 e foi fruto das reflexões sobre o impacto causado pela ciência e tecnologia na sociedade.

A incorporação de conteúdos escolares que abordem aspectos de CTS tem como objetivo principal a formação para a cidadania, incluindo, a capacidade de tomada de decisão por meio de uma abordagem que articule ciência, tecnologia e sociedade, concebendo a ciência como um processo social, histórico e não-dogmático.

O jogo desenvolvido, objeto da análise nesse artigo, é uma atividade lúdica. 0 termo lúdico tem origem na palavra latina ludus e se refere ao jogo ou aquilo que serve para divertir ou dar prazer. Uma definição mais completa é dada por Pinho:

O lúdico passou a ser reconhecido como traço essencial de psicofisiologia do comportamento humano. De modo que a definição deixou de ser o simples sinônimo de jogo. O lúdico apresenta valores específicos para todas as fases da vida humana. Assim, na idade infantil e na adolescência a finalidade é essencialmente pedagógica. (PINHO, 2017, p.1). 
O lúdico está presente desde os primórdios de nossa civilização e, segundo Araújo (1992), desde épocas anteriores a Cristo, já se tinha a preocupação com o valor dos jogos na vida das crianças. A educação greco-romana já atrelava o estudo à diversão, a partir dos conhecimentos de Aristóteles e Platão.

Huizinga (1999), no seu livro "Homo Ludens", afirma que o jogo é anterior e além da cultura humana, uma vez que os animais também jogam. Esse autor exemplifica sua afirmação lembrando as brincadeiras de filhotes de cachorros na grama.

Para Elkonin (1998), o jogo é uma preparação, um exercício para a vida adulta nos animais e no homem. Para Pinho (2017), o lúdico é caracterizado por dois elementos: o prazer e o esforço espontâneo. É prazeroso porque consegue reter a atenção das pessoas (no nosso caso, dos alunos), canalizando suas energias, criando um clima de entusiasmo que resulta em esforço espontâneo para atingir um objetivo específico. No desenvolvimento do jogo, procurou-se incorporar elementos gráficos que trouxessem o entusiasmo e o esforço espontâneo, tornando prazeroso o ato de jogar.

Segundo Maluf (2003), alguns benefícios da atividade lúdica na infância são: assimilação de valores, aquisição de comportamentos, aprimoramento de habilidades e socialização. Também, neste sentido, para Passerino (apud Vygotsky, 1989), o lúdico influencia enormemente o desenvolvimento do ser humano. É através do jogo que ele aprende a agir, que sua curiosidade é estimulada, que adquire iniciativa e autoconfiança, desenvolve a linguagem, o pensamento e a concentração.

Segundo Rolof (2010), o lúdico pode trazer à aula um momento de felicidade, seja qual for a etapa da vida do aluno, acrescentando leveza à rotina escolar e fazendo com que se registrem melhor os ensinamentos que lhe chegam.

Huizinga cita duas qualidades que os jogos devem possuir quando utilizados no contexto escolar, ao observar que "O jogo lança sobre nós um feitiço, é fascinante, cativante, está cheio das duas qualidades mais nobres que somos capazes de ver nas coisas: o ritmo e harmonia." (HUIZINGA, 2008, p. 12).

Segundo Cavalcanti e Soares (2009), os jogos vêm sendo utilizados por profissionais ligados à educação como um grande aliado para a construção educacional, pois desenvolve a expressão oral, a imaginação e a criatividade. 0 lúdico, a brincadeira, o jogo e tudo o mais envolvido com o ludismo representam um acesso ao desenvolvimento cognitivo, ao abastecer, enriquecer e diversificar as possibilidades experimentais e táteis do sujeito. De forma que um jogo de imersão com características construtivas proporciona um enriquecimento dessas possibilidades cognitivas.

Segundo Neves (2001), a criança e o jovem têm resistência ao processo tradicional escolar, porque ele não é lúdico nem prazeroso. Para Antunes (2017), a ludicidade pode possuir um caráter de competitividade, mas quando usada no ensino propicia momentos de descontração e fantasia, contribuindo para o aprendizado. No desenvolvimento do jogo, procurou-se proporcionar ao jogador momentos de 
descontração e fantasia, através da incorporação de elementos, tais como Easter Eggs $^{4}$ e símbolos a serem decifrados a partir de pesquisas na internet.

O jogo Chemistry Raiders, analisado nesse artigo, pretende enquadrar-se no que Kishimoto (1998) chamou de função educativa do jogo, pois completa o indivíduo em seus saberes, sua compreensão do mundo.

O jogo Chemistry Raiders é um jogo em primeira pessoa, ou seja, o jogador vê o cenário com a câmera nos olhos do jogador; existe ainda o jogo em terceira pessoa, que é um tipo de jogo em que a câmera está um pouco atrás do jogador, mostrandoo pelas costas.

Na Figura 2, pode-se observar a perspectiva de visão do jogador em um jogo 3D em primeira pessoa.

Figura 2 - Perspectiva de visão no jogo em primeira pessoa.

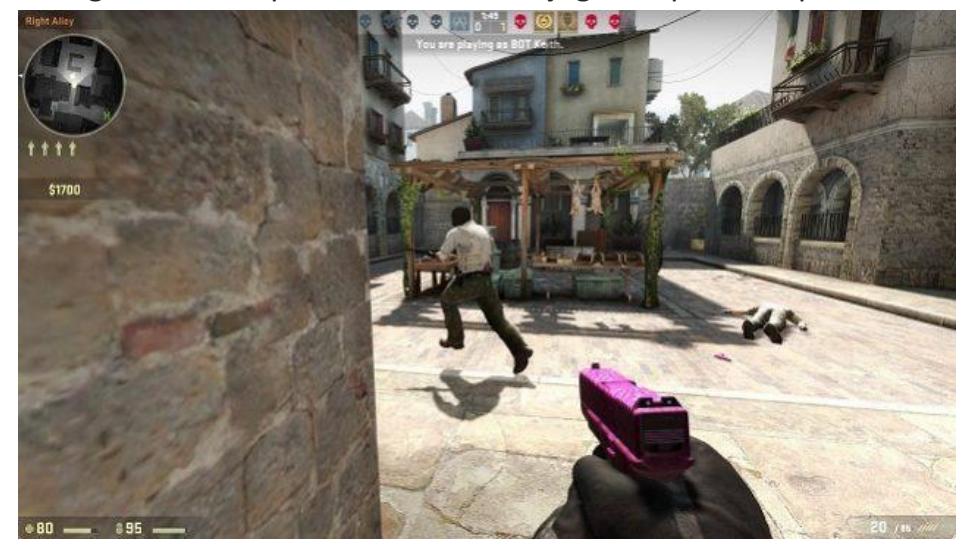

(Fonte: Site da web Beebom.com)

A escolha pelo jogo em primeira pessoa possibilitou simplificar a programação pois não é necessária introduzir um personagem fisicamente presente e visível, o que demandaria uma programação mais complexa.

Segundo Denisova (2015), um termo importante a ser considerado é a imersão, que é a sensação física da completa entrada no mundo digital, sendo esta característica almejada pelos jogadores em um jogo.

Então, a escolha por esse tipo de jogo seguiu 2 critérios:

a) Facilidade de programação;

b) Imersão completa no mundo digital.

A frase de Juul (1998) corrobora o sentido de imersão que se quer dar aqui:

O jogo de computador é uma atividade que ocorre com base em regras formalmente definidas e contendo uma avaliação dos esforços do jogador. Ao jogar um jogo, o resto do mundo é ignorado. (Juul, 1998, p.15).

\footnotetext{
${ }^{4}$ Easter egg é um termo que significa segredos e referências colocados, escondidos ou não, em uma obra. A princípio este termo foi criado para obras literárias e visuais, mas posteriormente se estendeu para o mundo de jogos. Nesse jogo existem alguns easter eggs escondidos, tanto fáceis quando difíceis de achar.
}

Página | 168

R. bras. Ens. Ci. Tecnol., Ponta Grossa, v. 12, n. 2, p. 164-187, mai./ago. 2019. 
A perspectiva de visão e outros elementos podem tornar um jogo mais atrativo, como, por exemplo, gráficos, sons, música, enredo e outros. Segundo Denisova (2015), o jogo em primeira pessoa pode proporcionar uma visão mais clara do cenário e consequentemente um grau de imersão maior; já o jogo em terceira pessoa pode proporcionar a visão total do personagem em ação, sem dar a sensação de que o jogador é o personagem.

Em termos de pesquisas desse tipo de jogo no mundo, pode-se destacar os trabalhos dos professores Eman Ahmad Shudayafat e Florica Moldoveanu, da Universidade Politécnica de Bucareste, que desenvolvem seus estudos sobre ambiente virtual 3D, realidade virtual, jogos e simulações computacionais (Shudayafat et al., 2015).

Segundo Schaverien (2001), o jogo virtual 3D é uma excelente ferramenta educacional porque oferece a oportunidade de visualizar, explorar, manipular e interagir com objetos e informações dentro do ambiente gerado pelo computador.

Para Shudayafat et al (2015), os alunos passam horas no mundo dos jogos, então, se o jogo contiver conhecimentos (por exemplo: químicos), ele pode representar uma grande aproximação na experiência do aprendizado. Os jogos 3D podem estimular a visão tridimensional, a criatividade, a competição, a interação social e o pensamento crítico. Para Tarja (2008), os softwares educativos com características de um jogo computacional são mais inteligentes e com maior aceitação por parte dos alunos.

\section{METODOLOGIA}

As perguntas feitas ao jogador, nas três fases do jogo, foram analisadas utilizando-se a análise de conteúdo descrita por Laurence Bardin.

Os fundamentos da análise de conteúdo, proposta por Laurence Bardin, foram usados para analisar o jogo, de acordo com as categorias pré-estabelecidas, particularmente, nas mensagens contidas nas questões propostas e no jogo Chemistry Raiders como um todo. A análise de conteúdo é um conjunto de técnicas de análise das comunicações que descreve e interpreta o conteúdo de documentos e texto, de acordo com Bardin (1977, p.31).

Para Bardin (1977), o objetivo maior da análise de conteúdo é a ultrapassagem da incerteza, na medida em que a leitura possa ser válida e generalizável, podendo ser partilhada por outras pessoas. $O$ enriquecimento da leitura, por um olhar atento, pode aumentar a pertinência dos dados, confirmando ou refutando a descoberta de conteúdos que se pretende demonstrar.

Análise de conteúdo, segundo esse mesmo autor, possui duas funções que podem ou não ser dissociadas: a função heurística, ou seja, a análise de conteúdo enriquece a tentativa exploratória e aumenta a probabilidade da descoberta de aspectos que se quer avaliar. A Análise de Conteúdo tem ainda a função de administração da prova, pois serve de diretriz para uma avaliação sistemática de confirmação ou refutação de um dado aspecto, a partir de hipóteses e questões provisórias. 
Também, Segundo Bardin (1977), a organização da análise segue a seguinte ordem cronológica: Pré-análise, Exploração do material, Tratamento dos Resultados, Inferência e Interpretação.

$\mathrm{Na}$ etapa de pré-análise, foi definido que seriam analisadas as questões propostas ao longo das fases do jogo. Para aspecto de ludicidade foi definido que seria analisado o jogo como um todo, seus ambientes, situações propostas e cenários.

Na etapa de exploração do material, foram escolhidas e agrupadas as categorias e unidades de registro usadas para descrever as características do conteúdo que se queria analisar. De forma que as categorias foram determinadas de acordo com o conteúdo analisado. As unidades de registro foram obtidas analisando-se as questões do jogo no caso com relação aos aspectos CTS e conteúdo de Química. Para a análise quanto a ludicidade, foi utilizado o jogo como um todo. Procurou-se escolher unidades de registro que fossem representativas do conteúdo que se queria analisar.

Os resultados obtidos na análise de aspectos CTS, conteúdos de Química e estímulo ao aprendizado de Química foram explicitados através de gráficos. Os resultados obtidos na análise, quanto à ludicidade do jogo, foram feitos de forma textual.

Os conteúdos de química e contextualização abordados no jogo foram: Coloides, soluções, Composição dos materiais, Solubilidade, propriedades coligativas, Saneamento básico tratamento de água, Termoquímica, Radioatividade e radiação, Fontes de energia, Ciência e cientistas.

O jogo desenvolvido para essa análise é um jogo 3D em primeira pessoa do tipo Open world, ou seja, o jogador pode acessar qualquer fase do jogo a qualquer momento se tiver credenciais para isso. Alguns jogos são caracterizados por possuírem fases subsequentes que, uma vez ultrapassadas, não podem ser novamente visitadas. Considerou-se que essa possibilidade não seria a mais adequada para esse jogo, pois a estratégia adotada foi a de que o jogador pudesse voltar a qualquer lugar do jogo a qualquer momento, para aprimorar seu entendimento de algum tema que foi abordado ou que gerou alguma dúvida. $A$ familiaridade do jogador com jogos computacionais 3D em primeira pessoa e seu conhecimento dos conteúdos de química farão com que ele termine o jogo em menor tempo.

O jogo foi desenvolvido para alunos do ensino médio, mas pode ser adaptado para alunos do ensino básico (Fundamental), por exemplo, no aprendizado sobre reciclagem e correta destinação de resíduos.

O jogo foi construído utilizando-se como ferramenta principal a game engine Unity3D. Essa game engine foi escolhida para a construção do jogo, pois dá ao programador a possibilidade de, com algumas modificações, compilar o jogo para diversas plataformas, tais como Android, Windows, Linux, Tizen, iOS, xbox360, Xbox One, Playstation 3 Smart TV entre outros. 


\section{RESULTADOS E DISCUSSÃO}

Para entender os critérios de escolha das categorias subcategorias e unidades de registro é necessário conhecer o contexto em que o jogo se desenvolve. Ressaltase aqui que esse objeto educacional está no repositório da UTFPR e vai ser enviado para o EDUCAPES.

O jogo Chemistry Raiders é ambientado em uma ilha, em algum lugar do oceano atlântico, que sofreu danos ambientais. A ilha possui três ambientes (fases). A parte natural da ilha foi evacuada em função dos danos ocorridos, restando apenas poucos animais; a parte urbana da ilha ainda é habitada, mas possui restrição de circulação em função da poluição atmosférica. Na indústria restaram poucos funcionários que trabalham em ambiente interno, devido ao alto grau de poluentes no ar.

O jogador é um explorador, com formação em Química, que chegou a ilha para verificar a extensão dos danos e relatar sua experiência a seus colegas que ficaram no continente.

Ele se depara com diversas situações problema, tenta resolvê-las, de forma que seu espírito aventureiro e ambientalista vem à tona. Seu objetivo é resolver as questões propostas, aprendendo com elas. Mostrando seu lado ambientalista, o jogador resolve coletar todos os lixos que encontra pelo caminho em todos os ambientes da ilha. Coletando os lixos, ele ganha pontos extras.

\subsection{Análise do jogo quanto à presença da abordagem CTS, estímulo ao aprendizado e conteúdo de Química.}

As categorias, subcategorias e unidades de registro para as análises feitas no jogo estão apresentadas na Tabela 1.

Tabela 1 - Categorias, subcategorias e unidades de registro das análises.

\begin{tabular}{|c|c|c|}
\hline Categorias & Subcategorias & Unidades de registro \\
\hline Abordagem CTS & $\begin{array}{c}\text { Ciência, Tecnologia, } \\
\text { Sociedade, Meio Ambiente. }\end{array}$ & $\begin{array}{l}\text { Ciência, científico, cientista, } \\
\text { tecnologia, tecnológico, catalisador, } \\
\text { nanotecnologia, eletrônica, motor, } \\
\text { elétrica, reatores, produção, } \\
\text { pessoas, sociedade, população, } \\
\text { urbanização, meio ambiente, } \\
\text { natureza, poluente, poluição, } \\
\text { decomposição, solo, biodegradável, } \\
\text { resíduo, ambiente, saúde, dejetos. }\end{array}$ \\
\hline $\begin{array}{l}\text { Conteúdos de } \\
\text { Química }\end{array}$ & Conteúdos de Química & $\begin{array}{l}\text { Composição, concentração, } \\
\text { volume, mistura, misturar, } \\
\text { temperatura, pressão, solução, } \\
\text { dissolver, dissolvido, sais, oxidação, } \\
\text { substâncias, reação, adição, } \\
\text { radioativo, ebulição. }\end{array}$ \\
\hline
\end{tabular}




\section{Estímulo ao}

aprendizado de

Química
Observar, montanha, no alto, veja, caminhar.

O número total de perguntas do jogo foi de 46 , sendo que algumas perguntas estiveram presentes em mais de uma categoria de análise. 0 número global de ocorrências das unidades de registro nas três categorias analisadas foi 67. A abordagem CTS e os conteúdos de química apresentaram 35 e 19 registros, respectivamente. As unidades de registro correspondentes ao estímulo ao aprendizado de Química tiveram apenas 13 ocorrências. Portanto, isto permite uma reflexão acerca da melhoria do jogo nesse aspecto. No Gráfico 1, são apresentados os números de questões, por ambiente do jogo, que abordam cada uma das 3 categorias principais da análise realizada.

Gráfico 1: Número global de ocorrência das categorias analisadas.

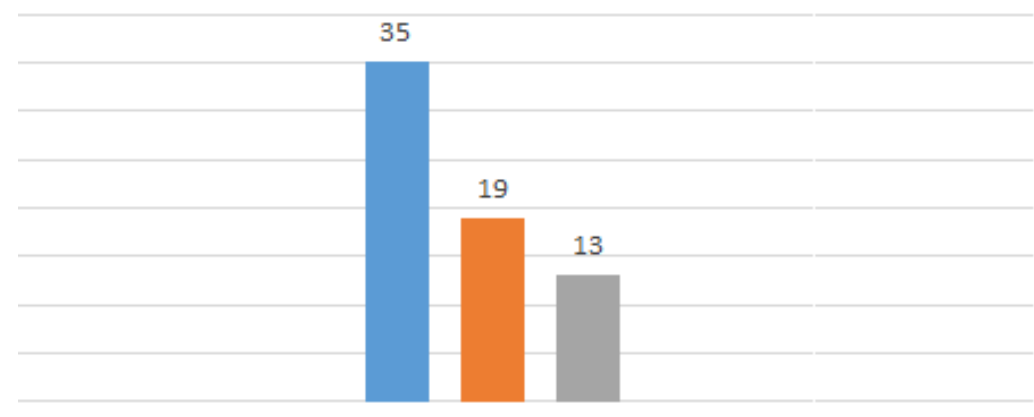

Abordagem CTS

- Conteùdos de Química

- Estímulo ao aprendizado de Química

O conteúdo proposto no jogo tem como pano de fundo a abordagem CTS e as preocupações com os danos ambientais causados pelos seres humanos. Todos os ambientes do jogo deixam claro que se deseja estimular a uma nova postura ética nos seres humanos sobre questões que envolvem o meio ambiente. $O$ foco do jogo é a preservação do meio ambiente para as gerações futuras. Todos os ambientes do jogo incentivam o jogador a descartar corretamente os resíduos encontrados ao longo do caminho. A degradação do ambiente é apresentada como problema em todas as fases. Esses contextos corroboram com o descrito por Silva e Censi (2015).

Para Silva e Censi (2015), torna-se inadiável uma relação positiva entre o meio ambiente e a sociedade, essa relação é determinante para a sobrevivência da espécie humana no planeta. Essa é a relação que se pretendeu estimular no jogo Chemistry Raiders, quando foram formuladas as questões propostas.

As respostas a serem dadas pelo jogador variam dentro do conteúdo proposto, de forma que o assunto não se torna repetitivo. Para Inkpen( 1995), Higgins (2000), Whitebread (1997), os jogos baseados em tentativas, erros e superação de desafios podem apoiar o desenvolvimento do pensamento lógico e a habilidade na resolução de problemas. O Jogo Chemistry Raiders explora o conteúdo de química com perguntas baseadas em alternativas que, se respondidas erradas, fornecem ao 
jogador a resposta correta, dando ao aluno oportunidade de aprender sobre o conteúdo proposto.

O gráfico 2 mostra o número de ocorrências por subcategoria de análise em cada ambiente do jogo. Percebe-se que as questões sobre meio ambiente estão concentradas na ambiente cidade. Isso é compreensível na medida em que a maioria dos seres humanos habitam as cidades, e os problemas ambientais gerados são, consequentemente, maiores. Portanto, esse gráfico mostra que as questões ambientais concentram-se na cidade, que é o espaço em que se reúnem a maioria dos impactos causados pelo avanço da tecnologia, e são esses impactos, segundo Santos (2008), devem ser analisados no processo escolar.

Gráfico 2. Número de ocorrências por subcategoria de análise, em cada ambiente.

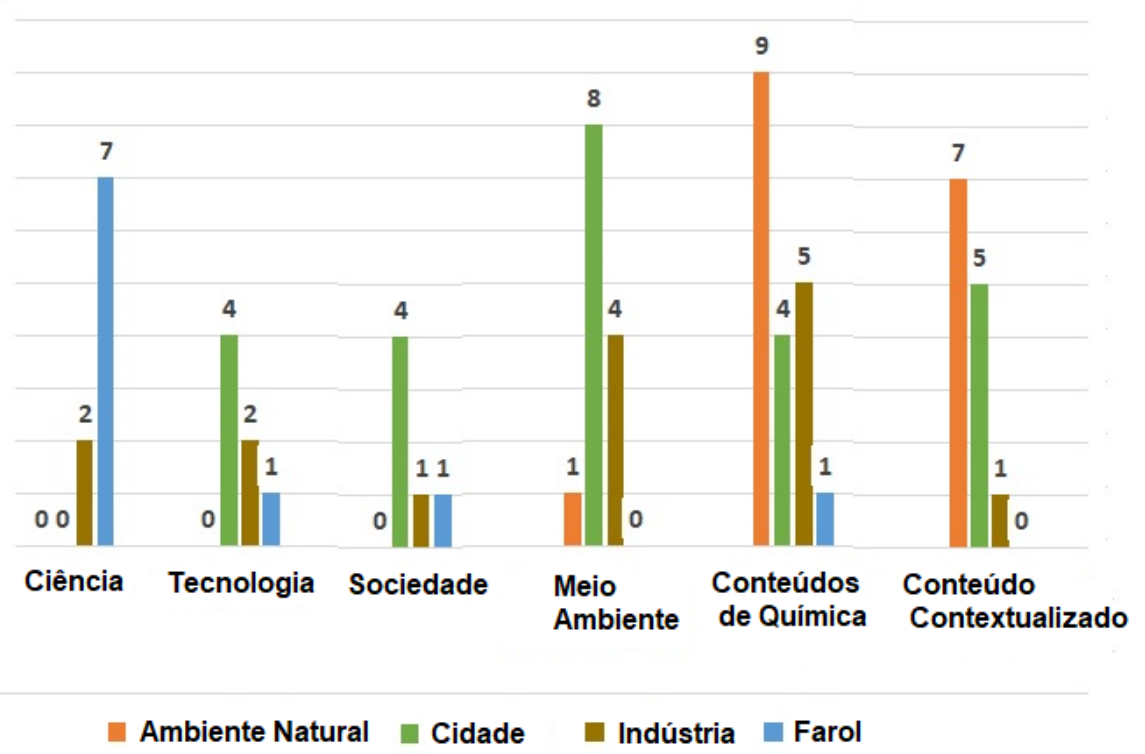

Observa-se que a maioria do conteúdo contextualizado está no ambiente natural, pois é onde se apresenta uma variedade maior de cenários e objetos 3D, possibilitando contextualizar as perguntas com os diversos cenários, tais como: o lago, o carro enferrujado e a montanha. Verifica-se também que grande parte do conteúdo de química foi contextualizado ao longo das fases do jogo, o que colocou o jogo dentro das premissas descritas por Ulicsak (2010).

Essa análise mostrou a ocorrência de uma alta densidade de conteúdos de química no jogo como um todo, o que permite afirmar que o Jogo Chemistry Raiders pode ser classificado como "Serious Game", segundo Protopsaltis et al. (2011), pois possui como característica principal o aprendizado dos conteúdos de química a partir do ambiente 3D.

A partir das situações vivenciadas pelo jogador, na observação do cenário, o professor pode trabalhar com o aluno temas controversos que vão desde poluição ambiental versus desenvolvimento social, até os impactos que a ciência e a tecnologia podem causar na sociedade. As discussões acerca dos impactos que a ciência e a tecnologia podem ter na sociedade ficam claras em todos os ambientes do jogo. Como exemplo, o professor pode abordar o impacto socioambiental causado pela descarga de dejetos no lago da indústria, ou então, o impacto causado 
pela descarga de esgoto dos prédios no mar do ambiente cidade. Existem exemplos de inter-relações que podem ser exploradas pelo professor ao longo do jogo, levando em conta a abordagem STS. A filosofia do jogo, portanto considera que o professor é o agente principal da mediação do processo ensino aprendizagem.

A subcategoria escolhida para verificar a presença de termos que caracterizem o estímulo ao aprendizado foi "conteúdo contextualizado". As unidades de registro escolhidas para essa subcategoria foram: observe, montanha, no alto, veja, caminhar. A contextualização dos conteúdos pode proporcionar um estímulo ao aprendizado de química na medida em que, segundo Watanabe (2011), estabelece inter-relações entre os conhecimentos escolares e os acontecimentos cotidianos da vida do aluno, permitindo uma interação entre "sujeito" e "objeto" que culmina na atribuição de reais significados aos conhecimentos químicos. Esses significados tornan-se fatores de estímulo para os alunos.

Segundo Soares (2008), expressões do tipo: "adorei o jogo"; "aprendi muito com o jogo"; "os alunos gostaram"; "os alunos querem mais", não mostram de fato se o jogo funcionou na aprendizagem do conceito. Precisa-se ir além, mostrando como o jogo auxiliou no ensino e aprendizagem do conceito. Nessa perspectiva, o jogo Chemistry Raiders por ser um jogo de perguntas e respostas de interação e de reflexão, tem seu principal foco no aprendizado dos conteúdos de química. $O$ aspecto lúdico e as características de um jogo 3D são apenas o veículo que os levará ao conteúdo de forma mais prazerosa e sólida.

O aspecto motivacional proporcionado pela contextualização dos conteúdos de química, segundo Silva (2013), chama a atenção do aluno e aguça a curiosidade, justificando a escolha pela subcategoria estímulo ao aprendizado.

Observa-se no gráfico 2 que houveram apenas 13 registros para essa categoria de análise e eles se deram em maioria no ambiente natural. Portanto, esse item foi pouco explorado, sendo um aspecto a ser melhorado no jogo. Entretanto, apesar de essa não estar presente de forma satisfatória, o aspecto audiovisual proporcionado pelo jogo estimula o jogador em sua criatividade, desenvolve capacidades pessoais e, consequentemente, tem o potencial de ser um estímulo ao aprendizado, suprindo em parte a deficiência verificada nesse item de análise.

\subsection{Análise do jogo quanto a aspectos que caracterizem ludicidade}

Esta análise procura identificar no jogo Chemistry Raiders elementos que caracterizem a presença de ludicidade. Para isso, foram escolhidas categorias de análise retiradas das afirmações feitas por Pinho (2017); Maluf (2003); Passerino (1989). As categorias a priori elencadas são as seguintes:

1) O lúdico é caracterizado por dois elementos: o prazer e o esforço espontâneo.

2) Os benefícios da atividade lúdica são: assimilação de valores, aquisição de comportamentos, aprimoramento de habilidades e socialização.

3) Através do jogo, a curiosidade humana é estimulada, possibilitando a iniciativa e a autoconfiança, desenvolvendo a linguagem, o pensamento e a concentração. 


\section{Categoria 1}

O Lúdico é caracterizado por 2 elementos: o prazer e o esforço espontâneo (Pinho 2017, p.1).

O jogo Chemistry Raiders é um jogo 3D em primeira pessoa, e essa classe de jogos traz uma representação da realidade para a tela dos computadores e smartphones.

Quando o jogador inicia o jogo, ele é apresentado à ilha de ChemGea ${ }^{5}$, na qual foram colocados elementos que simulam um ambiente natural, que foi projetado para dar ao jogador a sensação de que ele realmente está em um lugar de natureza exuberante.

Sabe-se que ambientes naturais trazem bem-estar e prazer aos seres humanos, então, transportou-se essa sensação de bem-estar para o ambiente virtual representado pelo jogo. Dessa forma, o jogador experimenta uma sensação de prazer ao percorrer os cenários oferecidos pelo jogo.

Como afirmou Raquel Pinho (2017), o esforço espontâneo caracteriza o lúdico. Esse esforço é percebido claramente nos jogos $3 \mathrm{~d}$ em primeira pessoa como Chemistry Raiders que, por representar o mundo real, estimula o jogador a ir em frente, explorar todos os ambientes, ganhar todos os pontos, obter todas as credenciais.

Como expresso por Ahmed Shudayfat (2015), os alunos passam horas no mundo dos jogos, e esse tempo demanda esforço. Se o jogo gerar interesse, o esforço se torna espontâneo. Gerar esforço espontâneo foi uma das principais diretrizes na concepção do jogo Chemistry Raiders. As características e a concepção do jogo, portanto, permitem concluir que o jogo proposto atende de forma positiva a essa categoria de análise.

\section{Categoria 2}

Os benefícios da atividade lúdica são: assimilação de valores, aquisição de comportamentos, aprimoramento de habilidades $e$ socialização (Maluf 2003, p.2).

A atividade lúdica, representada no jogo Chemistry Raiders, proporciona ao aluno a assimilação de valores, através das situações propostas nas suas três fases.

No ambiente natural, a questão 12 (Questão de número 12 do apêndice) aborda o tempo de decomposição de material ferroso na natureza, estimulando o aluno a refletir sobre os impactos causados pelo homem no ambiente. Esse estímulo tem como pano de fundo a assimilação de valores como cidadania e altruísmo.

No ambiente cidade, as questões de número dois, três, quatro, cinco, seis oito, nove, onze, doze e treze estimulam o aluno a refletir sobre questões ambientais, proporcionando da mesma forma a reflexão e a aquisição de valores que compõem

\footnotetext{
${ }^{5}$ Nome da ilha que compõe a totalidade do jogo
} 
a formação dos seres humanos para um convívio social adequado. Nos Quadros 1, 2 e 3 tem exemplos de questões propostas no ambiente cidade.

Quadro 1 - Questão de número 3 proposta no ambiente cidade

Algumas ações humanas no ambiente urbano interferiram na qualidade da água do rio que você está observando. Que ações inadequadas você pode identificar?

A) Ocupação das margens dos rios, pavimentação próxima às margens e descarte de resíduos tóxicos.

B) Dejetos lançados no rio, ocupação das margens e descarte de resíduos tóxicos.

C) Pavimentação próxima às margens, ocupação próxima à margem e dejetos lançados no rio.

D) Duas estão corretas.

Quadro 2 - Questão de número 5 proposta no ambiente cidade.

A urbanização que você está observando, ao percorrer esse caminho, tem algumas consequências, entre elas:

A) Estrangulamento (constrição) das seções de escoamento dos rios.

B) Impermeabilização do solo.

C) Chuva ácida.

D) $a$, b, e c estão corretas.

E) Somente a e c.

F) Somente a e b.

Quadro 3 - Questão de número 6 proposta no ambiente cidade.

Você está observando frascos de detergente. Sobre o impacto dos detergentes no ambiente, podemos afirmar:

A) Os íons fosfato em sua composição causam eutrofização, diminuindo a quantidade de oxigênio na água, causando a morte de peixes.

B) Os detergentes não oferecem riscos ao ambiente, pois são em sua maioria biodegradáveis.

C) Os detergentes biodegradáveis se degradam em poucas horas, não oferecendo riscos ao ambiente.

D) Duas estão corretas.

No ambiente indústria, de forma análoga aos outros ambientes, são explicitadas situações que estimulam o aluno a refletir sobre os aspectos ambientais da industrialização. Por exemplo: na cena em que ocorre o vazamento de um tanque de ácido na atmosfera, na cena em que ocorre o vazamento de resíduos no rio ou na presença de poluição atmosférica no ambiente da indústria. 
$\mathrm{O}$ aspecto de socialização pode estar presente no jogo, à medida que os alunos podem trocar informações entre si e com o professor sobre as questões propostas e situações problema criadas.

\section{Categoria 3}

Através do jogo, a curiosidade humana é estimulada, possibilitando a iniciativa e a autoconfiança, desenvolvendo a linguagem, o pensamento e a concentração (Passerino 1989, p.3).

O jogo Chemistry Raiders é um jogo repleto de dinamismo. O jogador, quando desembarca na ilha, observa um mundo a ser explorado e vai em frente. A partir da imediata visualização de lixo na areia da praia e por todo o ambiente, o aluno é estimulado a ter iniciativa e descartá-lo no recipiente adequado, pois isso resultará em pontos.

Ao percorrer cenários, como a montanha, o aluno desenvolve autoconfiança na expectativa de poder cair ou não, impelido a ir em frente. Da mesma forma, ao responder às questões, ele pode ou não acertá-las, o que cria também expectativa, já que a busca de sucesso - não querer errar a questão - estimula o pensamento e a concentração.

A partir das observações feitas, acredita-se que o jogo contemplou de forma positiva a terceira categoria de análise, corroborando as ideias de Passerino (1989).

A terceira análise feita no jogo indicou que, de forma geral, o jogo Chemistry Raiders pode ser classificado como atividade lúdica, à medida que atende, de forma satisfatória, às características desejáveis, segundo os autores selecionados.

\section{CONSIDERAÇÕES FINAIS}

As análises realizadas nas questões do jogo mostram que os conteúdos de físico química propostos foram contemplados nos três ambientes do jogo, contextualizando o conteúdo de forma adequada. A abordagem CTS dos conteúdos mostrou-se satisfatoriamente presente nas 3 fases, portanto, espera-se que o jogo possa ser usado nesse contexto. A análise feita no jogo como um todo permitiu concluir que ele contempla as afirmações feitas por Pinho (2017); Maluf (2003); Passerino (1989), podendo ser caracterizado como atividade lúdica. Conclui-se que o jogo 3D em primeira pessoa, representado aqui pelo jogo Chemistry Raiders, pode se constituir em uma atividade lúdica para ensinar os conteúdos propostos dentro do contexto CTS.

Pesquisas realizadas em anais de eventos como ENEQ, ENPEQ, e em revistas como Química nova na escola, demonstram a inexistência de trabalhos que abordam os jogos computacionais 3D em primeira pessoa no Brasil. Existem apenas algumas poucas análises de aplicabilidade de jogos 2D no ensino. Portanto, torna-se relevante o desenvolvimento de um objeto educacional como o Jogo Chemistry Raiders, que foi criado no âmbito acadêmico, focado especificamente para as atividades educacionais. 
Em nível mundial, observa-se que o tipo de jogo proposto nesse trabalho é muito estudado, sobretudo no Reino Unido, Estados Unidos da América e Romênia.

Espera-se que um jogo dessa dimensão possa constituir um marco no desenvolvimento de pesquisas sobre jogos 3D em primeira pessoa no Brasil. 


\title{
First person 3D computer game: a possibility for teaching of chemistry
}

\begin{abstract}
In the last two decades, the use of computers has intensified in the school environment. The technology involved in the computational environment has become inseparable from students' daily life, so playfulness has gained importance and computer games have become routine. This article analyzes a first-person 3D computer game that deals with PhysicsChemistry contents in the context of the Science, Technology and Society (CTS) approach. The questions proposed in the game are analyzed as an objective to identify the presence of CTS aspects, contents of Chemistry and situations that characterize the stimulus to learning. The playful character is analyzed in the game as a whole. The analyzes are based on Laurence Bardin's content analysis methodology. The results obtained in the analyzes indicate that it adequately contemplates the proposed chemical contents, within the context of the CTS approach and has the characteristics that make it a playful activity, appropriate for teaching.
\end{abstract}

KEYWORDS: STS. Chemical education. Computational games. Playfulness. 


\section{REFERÊNCIAS}

ANTUNES, C.C, O lúdico como ferramenta didática e o seu uso no ensino de língua portuguesa. Revista Eletrônica - INESUL - Instituto de Ensino Superior de Londrina. Londrina/Pr. pág.8vol.48.2017. Disponível em:

$<$ https://www.inesul.edu.br/revista/arquivos/arq-idvol 48 1490045656.pdf>. Acesso em: 02/12/2018.

ARAÚJO, V. C. O jogo no contexto da educação psicomotora. São Paulo: Cortez, 1992.

BARDIN.L. Análise de conteúdo. Lisboa: Editora Edições 70, 1977.

CAVALCANTI, E. L. D. SOARES, M. H. F. B. O RPG como estratégia de problematização e avaliação do conhecimento químico. Revista Electrónica de Enseñanza de las Ciências, v. 8, p. 255-280, fev/março.2009.

DENISOVA.A; CAIRNS.P. First Person vs. Third Person Perspective in Digital Games do Player Preferences Affect Immersion. 2015.

ELKONIN, D. B. Psicologia do jogo. São Paulo, Martins Fontes 1998.

HIGGINS, S. The logical zoombinis.Teaching Thinking, Vol 1 Issue 1, 2000.

HUIZINGA, J. Homo Ludens. São Paulo: Perspectiva, 2008.

INKPEN, K.M.; BOOTH.; K.S.; GRIBBLE, S.D.; ANDKLAWE M.M. Give and take: children collaborating on one computer, in JM Bowers and SD Benford Human Factors in Computing Systems, Denver, CO, ACM Conference companion, pág 258259, 1995

JUUL, J. A. Clash between Game and Narrative, DAC Conference, Bergen, Norway, 1998.

KISHIMOTO, T. M. O brincar e suas teorias. São Paulo: Pioneira, 1998.

MALUF, A.C. M. A Importância das Atividades Lúdicas na Educação Infantil. Rio de Janeiro, 2003. Disponível em: <http://www.profala.com/arteducesp178.html>. Acesso em: $10 / 11 / 2017$. 
NEVES, L.O.R. O Lúdico nas interfaces das relações educativas.

Disponível em:

$<w w w . d e f . u n i r . b r / . . . / 2847$ texto6.1__o_ludico_nas_interfaces_das_relacoes_ed ucativas.pdf>. Acesso em: 19 ago. 2018

PASSERINO, L. M. Avaliação de jogos educativos computorizados. Disponível em <http://www.c5.cl/tise98/html/trabajos/jogosed/index.htm> Acesso em: 12/08/18. 1998.

PINHO, R. O lúdico no processo de aprendizagem, São Paulo jun.2017.webartigos. Disponívelem: <http://www.webartigos.com/artigos/o-ludico-no-processo-deaprendizagem/21258/> .Acesso em 19 de ago. 2018.

PROTOPSALTIS A.; PANNESE L.; PAPPA D.; HETZNER S. Serious Games and Formal and Informal Learning. Disponível em $<$ http://elearningpapers.eu/en/article/Serious-Games-and-Formal-and-InformaLLearning >. Acessado em $10 / 10 / 2017>$.

ROLOFF E.M. A importância do lúdico em sala de aula de aula. Semana de Letras e Escrita Criativa. Disponível em:

$<$ http://ebooks.pucrs.br/edipucrs/anais/Xsemanadeletras/comunicacoes/EleanaMa rgarete-Roloff.pdf>. Acesso em: 6/11/2018.

SANTOS, W. L. P. Educação ambiental por meio de tema CTSA: Relato e análise de experiência em sala de aula. XIV Encontro Nacional de Ensino de Química (XIV ENEQ), Curitiba, 2008.

SANTOS, W. L. P.; MÓL, G.S.; DIB, S.M.F.; MATSUNAGA, R.T.; SANTOS, S.M.O.; CASTRO, E.N.F.; SILVA, G.S.; FARIAS, S.B. Química Cidadã volume 2a edição. Editora AJS, São Paulo 2013.

SANTOS, W. L. P.; SCHNETZLER, R. P. Educação em química: compromisso com a cidadania. Ijuí: UNIJUÍ, 1997.

SCHAVERIEN.L. "Teacher Education in Generating Virtual Classroom: $\mathbf{A}$ Web Delivered Context for Developing Learning Theories", J. of Bibliographic Research, vol. 20, pág. 5. International Journal of Science Education Volume 25, pág. 5. 2003.

SHUDAYAFAT, E. A.; MOLDOVEANU, F.; MOLDOVEANU, A.; GRADINARU, A.; DASCALU, M.I. 3D Game-Like Virtual Environment for Chemistry Learning. 
Universitat Politecnica Bucuresti. Scientific, Bulletin Séries C, v. 77, n. 1, pág. 15-26, 2015.

SILVA. E. L. Cotidiano e Contextualização no Ensino de Química. Revista Química nova na escola. 5, № 2, pág. 84-91, maio 2013.

SILVA, R.H.; CENSI R.D.; Multiculturalismo e Educação Ambiental Reflexões Acerca da Construção de uma Nova Postura Ética dos Seres Humanos. Revista contexto \& Educação Editora Unijuí Ano 30 no 97 Set. /Dez. 2015.

TARJA, S. The Challenge of Managing Affordances in Computer Game Play. Human

It VKPEOMMUFW, UPÓNMVK. Published by the University College of Borå Estocolmo. 2008.

TEIXEIRA, P. M. M. Educação científica e movimento CTS no quadro das tendências pedagógicas no Brasil. Revista Brasileira de Pesquisa em Educação em Ciências, Belo Horizonte, v. 3, n. 1, p. 88-102, 2003.

ULICSAK, M.; WRIGHT, M. Games in Education: Serious games. Bristol, Futurelab literature review, 2010.

VYGOTSKY, L. S. A Formação Social da Mente. São Paulo: Martins Fontes, 1989.

WATANABE, L. A. O papel da contextualização e da interdisciplinaridade no ensino de química. 9 SIPEQUI. Simpósio brasileiro de educação química. Natal /RN. 2011.

WHITEBREAD, D. Developing children's problem solving: the educational uses of adventure games, in: McFarlane, An Information Technology and Authentic Learning. London: Routledge, 1997. 
Apêndice: Algumas questões propostas no jogo.

\section{Ambiente Natural}

Observe o ambiente natural a sua frente e responda: qual a origem dos sais que estão dissolvidos na água do lago?
A) Já estavam na água desde sua origem.
B) Foram trazidos diretamente pelas chuvas.
C) Vieram do solo, arrastados pelas chuvas.

O movimento contínuo de precipitação e evaporação da água, que você está observando, recebe o nome de:
A) Chuva.
B) Ciclo da água.
C) Ciclo do solo.
D) Evaporação.

A água doce que você observa a sua frente:
A) Sempre esteve no local.
B) Tem origem exclusivamente da chuva.
C) Tem origem dos aquíferos subterrâneos alimentados pelas chuvas.

Ao caminhar por este ambiente você está observando rochas cuja composição predominante é o granito. Observando sua aparência, você poderia classificá-las como:
A) Homogêneas.
B) Heterogêneas.
C) Mistura homogênea.

Observe a fogueira que está a sua frente. Ela é constituída principalmente de $\mathrm{CO}_{2}(\mathrm{~g})$, $\mathrm{CO}(\mathrm{g})$ e C(s). A fumaça emitida por ela pode ser classificada como:
A) Solução.
B) Colóide.
C) Agregado. 


\section{Ambiente Cidade}

A estrutura que decora o topo da fonte da praça é o Fulereno C60, a terceira mais estável forma alotrópica do carbono. Sobre ela pode-se afirmar:

A) Possui hidrogênio ligado ao carbono na molécula.

B) Entre as várias áreas de aplicação dos Fulerenos estão a eletrônica, a medicina e os foguetes.

C) Existem poucos e controversos estudos sobre a toxicidade dos Fulerenos, se compararmos com estudos sobre sua aplicabilidade.

D) Duas estão corretas.

E) Todas estão corretas.

A maior parte da poluição da água no ambiente urbano ocorre principalmente:

A) Devido às chuvas que carregam os poluentes, os quais compõem naturalmente o ar.

B) Pela interação humana com o meio ambiente.

C) Ocorre naturalmente no ciclo da água.

Algumas ações humanas no ambiente urbano interferiram na qualidade da água do rio que você está observando. Que ações inadequadas você pode identificar?

A) Ocupação das margens dos rios, pavimentação próxima às margens e descarte de resíduos tóxicos.

B) Dejetos lançados no rio, ocupação das margens e descarte de resíduos tóxicos.

C) Pavimentação próxima às margens, ocupação próxima à margem e dejetos lançados no rio.

D) Duas estão corretas.

Você está observando 4 materiais: madeira, metal, plástico, pneu e vidro, os quais foram descartados no rio que fica ao lado dessas casas. Qual é aproximadamente o tempo de decomposição desses materiais?
A) 13 anos, 100 anos, 100 anos, indeterminado, Indeterminado.
B) Indeterminado, indeterminado, 100 anos, 13 anos, 100 anos.
C) 100 anos, Indeterminado, 13 anos, 100 anos, Indeterminado. 


\section{Ambiente Indústria}

A indústria armazenou esses tonéis que contem resíduos com baixa radioatividade usados no processo industrial. Sobre seu armazenamento:

A) Está correto, pois tonéis metálicos conseguem reter $100 \%$ das radiações ionizantes.

B) Está correto, pois basta sinalizar o resíduo.

C) Está errado, pois radiação ionizante (gama) não é retida por tonéis metálicos com $2 \mathrm{~mm}$ de espessura.

D) Duas estão corretas.

Você está observando uma indústria. Sobre a sua localização, responda:
A) É adequada, pois está perto do ambiente urbano.
B) É adequada, pois está próximo ao rio, facilitando o descarte de dejetos.
C) Inadequado, pois está perto do ambiente urbano e do natural.

Existe um laboratório nessa indústria. Sobre sua facilidade de acesso em caso de acidente responda:
A) Está bem localizado não oferecendo dificuldades para evacuar em caso de acidente.
B) Está mal localizado, pois as caixas dificultam a evacuação.
C) Está bem localizado, pois as caixas podem ser removidas facilmente.
D) Duas estão corretas.

Você está observando o aquecimento de 3 compostos nos Erlenmeyers: água, álcool e acetona. Qual sequência correta dessas substâncias da mais volátil para a menos volátil?
A) Água, álcool, acetona.
B) Acetona, água, álcool.
C) Álcool, água, acetona.
D) Acetona, álcool, água.
E) Água, acetona, álcool.

Se você adicionar $\mathrm{NaCl}$, que está dentro de um dos tubos de ensaio na mesa a direita, ao erlenmeyer que contém água em ebulição ocorre:
A) O aumento da pressão de vapor da água.
B) A diminuição da pressão de vapor da água. 
C) Acelera a ebulição.

D) Retarda a ebulição.

E) Nada é alterado.

F) Duas estão corretas.

Farol

Dois desses cientistas divergiram quanto à estrutura espacial da molécula de cloreto de hexamino-cobalto (III), travando uma batalha que contribuiu para desenvolvimento da química de coordenação. Quais foram esses cientistas?
A) Lavoysier e Mendlejev.
B) Werner e Marie Currie.
C) Linus Pauling e Jørgensem.
D) Werner e Jørgensem.
E) Linus Pauling e Werner.

Um dos cientistas dessa sala foi o responsável por disseminar uma cultura que prega a ingestão de doses diárias de vitamina C. Esse cientista foi:
A) Avogadro.
B) Marie Currie.
C) Linus Pauling.
D) Lavoysier.

Um dos cientistas dessa sala iniciou os estudos de um fenômeno que ocorre com partículas subatômicas, que Marie e Pierre Currie utilizaram posteriormente em suas pesquisas. Esse cientista foi:
A) Gay-Lussac.
B) Proust.
C) Carnot.
D) Röntgen.

Um dos cientistas dessa sala derrubou definitivamente a teoria da geração espontânea de Aristóteles, usando uma vidraria chamada pescoço de cisne. Esse cientista foi:
A) Röntgen.
B) Gay-Lussac.
C) Proust. 
Um desses dois cientistas deu seu nome a uma associação beneficente que atua na área de saúde. Esse cientista foi:
A) Becquerel.
B) Cezar Lattes.

Recebido: 2018-04-02

Aprovado: 2019-02-11

DOI: $10.3895 /$ rbect.v12n2.8120

Como citar: RIBAS, H. L. R. L.; HUSSEIN, F. R. G. S.; MARQUES, C. A. Jogo computacional 3D em primeira pessoa: uma possibilidade para o ensino de química. Revista Brasileira de Ensino de Ciência e Tecnologia, v. 12, n. 2, 2019. Disponível em: <https://periodicos.utfpr.edu.br/rbect/article/view/8120>. Acesso em: xxx. Correspondência: Haroldo Luis Ribas Luis Ribas - haroldordr@yahoo.com.br Direito autoral: Este artigo está licenciado sob os termos da Licença Creative Commons-Atribuição 4.0 Internacional. 